\title{
Heyelan Duyarlılık Haritalarının Üretilmesinde Analitik Hiyerarşi Yönteminin Ve Coğrafi Bilgi Sistemlerinin Kullanımı*
}

\author{
Majid Aghlmand ${ }^{1}$, Mehmet İnanç Onur ${ }^{* * 1}$, Reza Talaei ${ }^{3}$ \\ ${ }^{1}$ Eskişehir Teknik Üniversitesi, İnşaat Müh. Bölümü, Eskişehir, Türkiye (ORCID: 0000-0003-0534-5393) \\ 1 Eskişehir Teknik Üniversitesi, İnşaat Müh. Bölümü, Eskişehir, Türkiye (ORCID: 0000-0002-2421-4471) \\ 3 Soil Conservation and Watershed Management Research Department, Ardabil Agricultural and Natural Resources Research and Education Center, Ardabil, Iran \\ (ORCID: 0000-0001-8717-0333)
}

(Konferans Tarihi: 5-7 Mart 2020)

(DOI: 10.31590/ejosat.araconf28)

ATIF/REFERENCE: Aghlmand, M., Onur, M. İ \& Talaei, R. (2020). Heyelan Duyarlılık Haritalarının Üretilmesinde Analitik Hiyerarşi Yönteminin Ve Coğrafi Bilgi Sistemlerinin Kullanımı. Avrupa Bilim ve Teknoloji Dergisi, (Özel Sayı), 224-230.

\section{$\ddot{O} z$}

Depremler ve heyelanlar toplum hayatını derinden etkileyen doğal afetlerin başında gelmektedir. Özellikle dağlık bölgelerde meydana gelen heyelanlar, her yıl can kaybına ve hasara sebep olmaktadır. Son yıllarda heyelana duyarlı bölgelerin belirlenmesi çalışmaları oldukça yaygınlaşmıştır. Heyelan duyarlılık analizlerinin yapılması hem mühendislik projelerinin planlanmasını kolaylaştıracak hem de meydana gelebilecek zararların azaltılmasını sağlayacaktır. Bu çalışmada, İran'ın Ardabil (Erdebil) bölgesindeki Saqezchi'in heyelan duyarlılık haritaları oluşturulmuştur. Heyelan duyarlılık analizinde arazi kullanımı, yağış miktarı, faylara uzaklık, litoloji, akarsu ağlarına uzaklık, yükselti, eğim, bakı ve yola uzaklık parametreleri kullanılmıştır. Çalışmada heyelan duyarlılık haritası oluşturulurken Analitik Hiyerarşi Süreci (AHP) yöntemi ve Coğrafi Bilgi Sistemleri (CBS) kullanılmıştır. Oluşturulan duyarlılık haritaları, "çok yüksek, yüksek, orta, düşük ve çok düşük" duyarlı alanlar olmak üzere 5 grup altında sınıflandırılmıştır.

\section{The Use of Analytical Hierarchy Process and Geographic Information Systems in Production of Landslide Susceptibility Maps}

\begin{abstract}
Earthquakes and landslides are among the natural disasters that deeply affect social life. Landslide, especially occurs in mountainous areas, causes loss of life and damages every year. Studies to determine landslide sensitive areas have become quite widespread in recent years. Conducting landslide susceptibility analysis will both facilitate the planning of engineering projects and reduce the loss. In this study, landslide susceptibility maps of Saqezchi in Ardabil (Ardebil) region of Iran are created. In landslide susceptibility analysis; land use, rainfall, distance to faults, lithology, distance to river networks, elevation, slope, aspect and distance to road parameters are used. Analytical Hierarchy Process (AHP) method and Geographic Information Systems (GIS) are used while creating landslide susceptibility map. The created sensitivity maps are classified under 5 groups as "very high, high, medium, low and very low" sensitive areas.
\end{abstract}

Keywords: Landslide, Geographic Information Systems, Analytical Hierarchy Process, Ardabil.

\footnotetext{
${ }^{*}$ Bu makale International Conference on Access to Recent Advances in Engineering and Digitalization (ARACONF 2020) de sunulmuştur. 


\section{Giriş}

Heyelanlar önemli doğal afetler arasında yer almakta olup, sıkça can ve ekonomik kayıplara neden olmaktadır. Heyelanlar, genellikle bir şevi oluşturan kaya veya zeminin suyun taşıyıcı etkisi olmadan, yerçekimi sebebiyle harekete geçmesi olarak tanımlanır (Crozier, 1986). Heyelanlar yapılarda hasara sebep olduğu gibi yerleşim merkezi dışındaki yollar ve tarım alanlarına da zarar vermektedir.

Dünya genelinde olduğu gibi İran içinde depremlerden sonra heyelan ikinci en önemli doğal afettir. Ardabil bölgesinde görülen heyelanlar, her yıl altyapı sistemlerine büyük zararlar vermektedir. Ayrıca, yeni heyelan oluşumları bölgede imar faaliyetlerini zorlaştırmıştır (Wang vd., 2006; Ilinca vd., 2011; Dai vd., 2001; Yesilnacar ve Topal, 2005; Westen vd., 1999; Özşahin, 2014) Heyelanların sosyo-ekonomik etkilerinin artması dünya çapında analiz ve araştırmaları yoğunlaştırmıştır Bir bölgedeki şevin heyelan analizi jeolojik, jeomorfolojik ve hidrojeolojik faktörlere göre gerçekleştirilmektedir. Heyelana duyarlı bir alanın analizi ve riskin tam olarak belirlenmesi, o bölge ve toplum için çok önemlidir (Özşahin, 2014). Heyelana duyarlı bir alanda, arazi kullanım planlaması veya inşaat programı olası heyelan riskine göre yapılmalıdır. Heyelan tehlikesi ve risk analizi, geçmiş heyelanların ve özelliklerinin tanımlanması ve verilere göre gelecektekilerin tahmin edilmesi için kullanılabilir.

Dünyada farklı yöntemler uygulanarak heyelan tehlikesini değerlendirmek ve duyarlılık haritaları üretmek için birçok araştırma yapılmıştır (Corominas vd., 2014; Feizizadeh vd., 2014). Bu çalışmalara bakıldığında, büyük çoğunluğunun olasılıksal modeller kullanılarak yapıldığı görülmektedir (Lee ve Dan, 2005; Talaei vd., 2004; Cevik ve Tolap, 2003; Talei, 2014; Akgun ve Türk, 2010; Clerici vd., 2006; Lee ve Min, 2001) Karar ağacı, yapay sinir ağları, bulanık mantık gibi veri madenciliği yöntemleri de heyelan duyarlılık değerlendirmesinde son çalışmalarda sıklıkla görülen yöntemler arasında yer almaktadır (Akgun ve Türk, 2010; Clerici vd., 2006; Lee ve Min, 2001). Bu araştırmalarda kullanılan yöntemlerden birisi de Coğrafi Bilgi Sistemleri (CBS) olup, sıkça uygulanmakta ve sürekli geliştirilmektedir. CBS heyelan oluşumuna neden olan tüm faktörleri sistemli ve yüksek bir hassasiyetle analiz edilebilmektedir. Son günlerde heyelan duyarlılık haritası çalışmalarında CBS yanı sıra Analitik Hiyerarşi Süreci (AHP) yöntemi de kullanılmaktadır. (Saaty ve Brandy, 2009; Zahedi, 1986).

Literatürde, İran'ın Ardabil bölgesindeki heyelanlar üzerine birçok araştırma bulunmaktadır (Uromeihy ve Mahdavifar, 2000; Talaei, 2014; Mohammady vd., 2012; Feizizadeh ve Blaschke, 2013). Ancak, AHP yöntemi nadir olarak uygulanmıştır. Bu çalışmada İran'ın Ardabil bölgesindeki Saqezchi ilçesinin heyelan duyarlılık haritalarının AHP yöntemi ile CBS teknikleri kullanılarak hazırlanması amaçlanmıştır. Çalışmada heyelan duyarlılık haritaları oluşturulmuş ve "çok yüksek, yüksek, orta, düşük ve çok düşük" duyarlı alanlar olmak üzere 5 grup altında sınıflandırılmıştır.

\section{Materyal ve Metot}

\section{1. İnceleme Alanı ve Genel Özellikleri}

İnceleme alanı, İran'ın kuzeybatısında yer almakta olup, İran coğrafi bölgelerine göre Güney Azerbaycan Bölgesinde bulunan Ardabil şehridir. İl alanı, kuzeyden Azerbaycan Cumhuriyeti, batıdan Doğu Azerbaycan Eyaleti, güneybatıdan Gazvin Eyaleti,

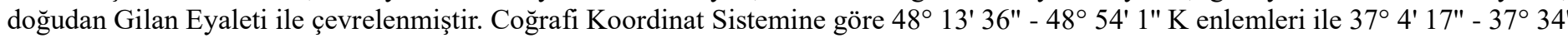
16" D boylamları arasındadır. Yüzölçümü ise $1758.45 \mathrm{~km}^{2}$ olup genel yerleşim Şekil 1 'de gösterilmiştir. Şekil 2' de ise bölge için geçmiş kayıtlı heyelanların haritası verilmiştir.
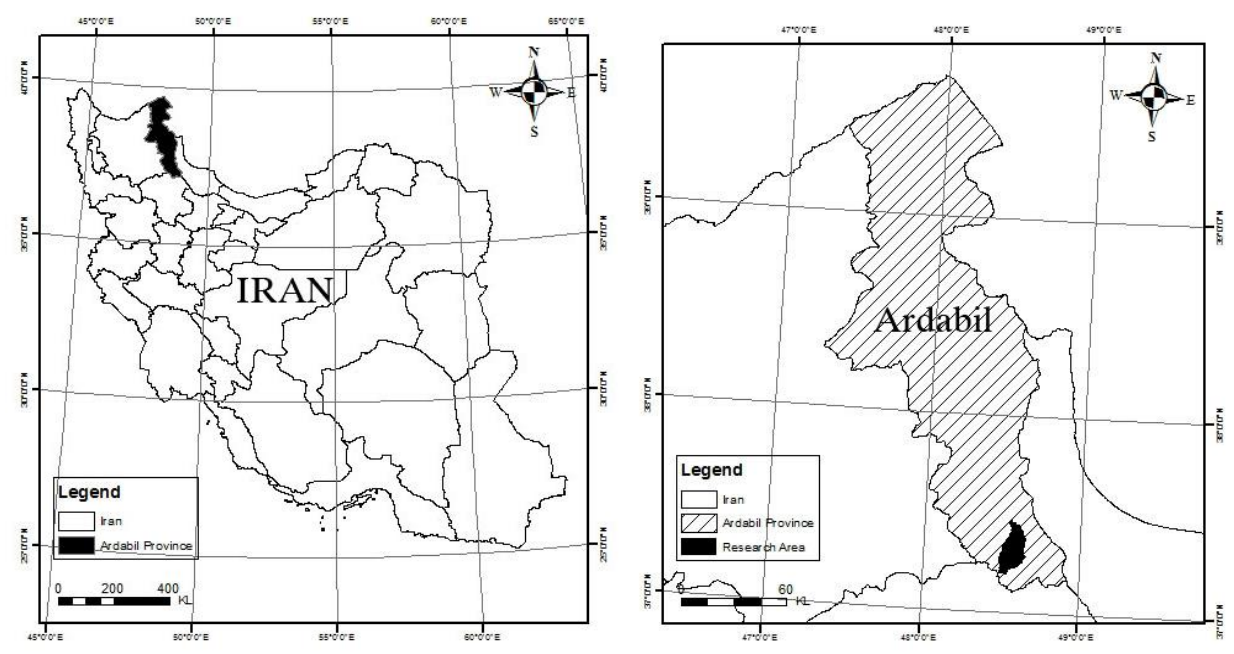

Şekil 1. Çalışma alanı 


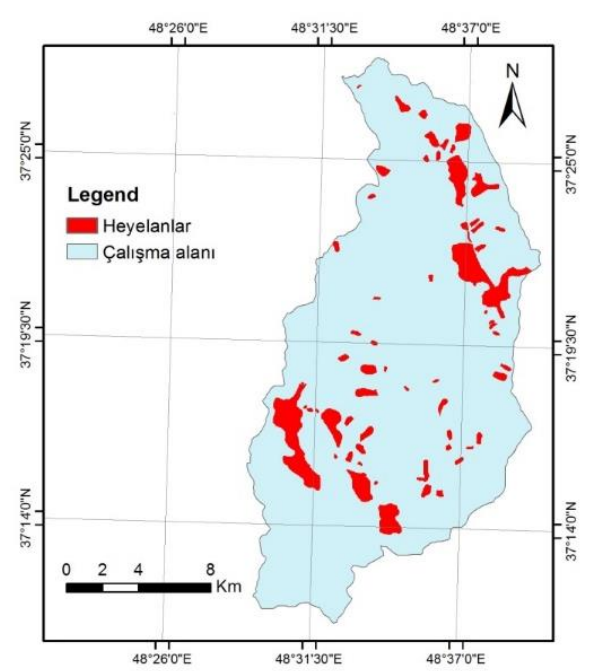

Şekil 2. Geçmiş heyelanların haritası

\subsection{Veri analizi}

Heyelanlar üzerinde çeşitli faktörlerin etkisi bulunmaktadır (Tabatabaei, 1998; Uromeihy ve Mahdavifar, 2000). Her bir faktörün heyelan üzerindeki etkisini belirlemek için farklı verilere ihtiyaç duyulmaktadır. Bu faktörler, arazi kullanımı, yağış miktarı, faylara uzaklık, litoloji, akarsu ağlarına uzaklık, yükselti, eğim, bakı, yola uzaklıktır. Bu çalışmada bu faktörlere ait haritalar için İran Tarım ve Orman Bakanlığı'nın farklı veri tiplerinden yararlanılmıştır. Haritalar Şekil 3, 4, 5 'de sunulmuştur. Haritaların hazırlanmasında dikkate alınan faktörler ve ağırlıkları ise Tablo 1'de verilmiştir.

Literatürde sıkça karşılaşılan çalışmalara benzer şekilde görüntü analizleri ve tüm faktörleri içeren haritalarının üretilmesinde CBS tabanlı yazılımlardan ArcGIS/ArcMap isimli paket program kullanılmıştır.
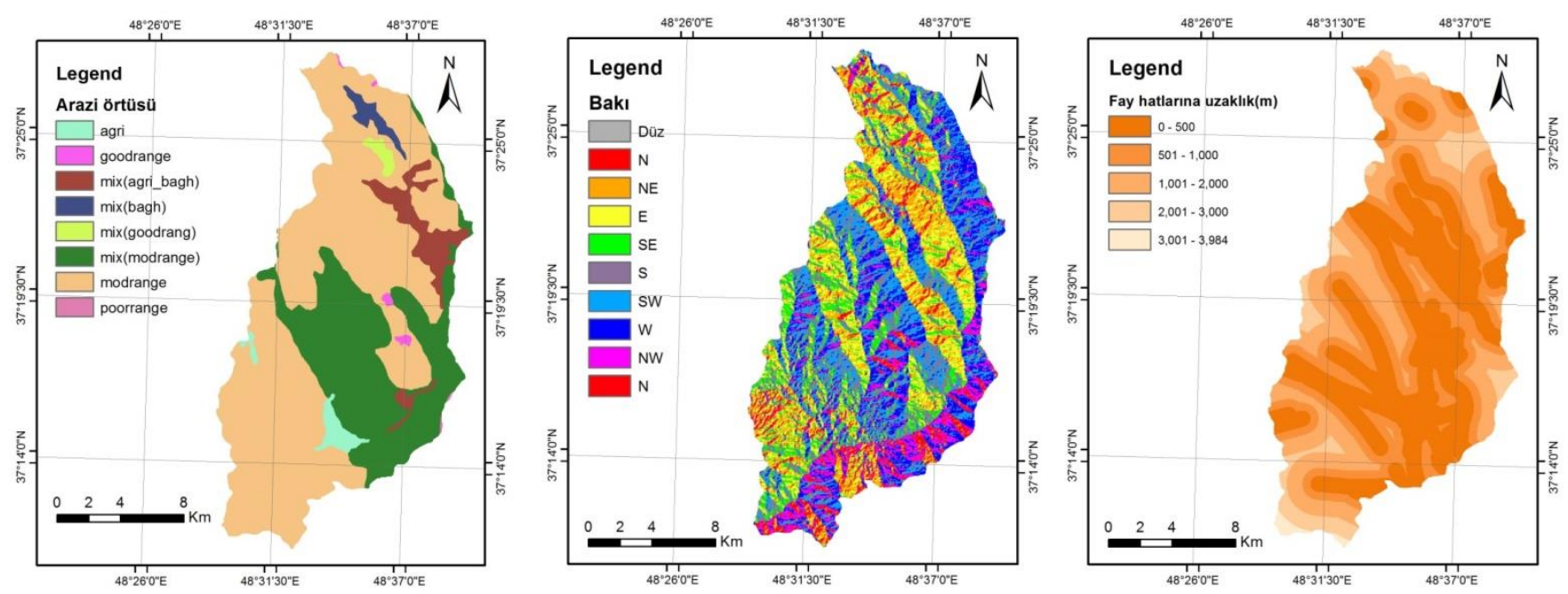

Şekil 3. Arazi örtüsü, bakı ve fay hatlarına uzaklık haritaları 

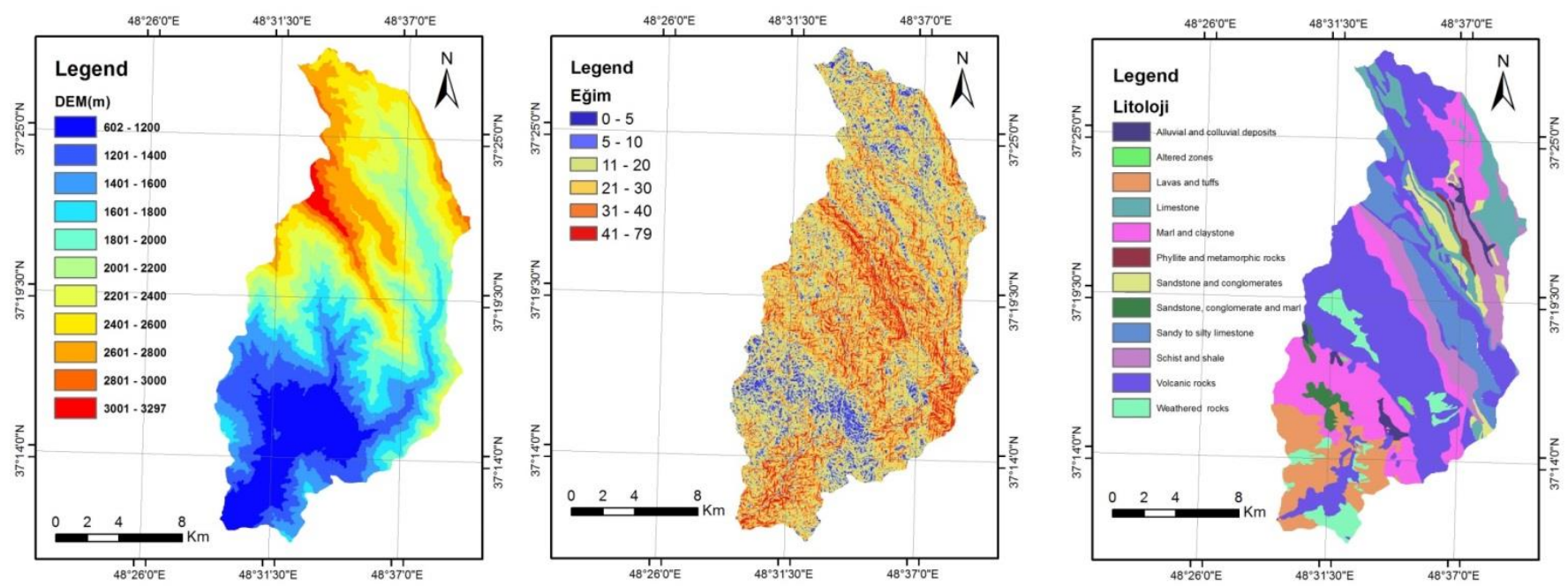

Şekil 4. Yükseklik, eğim ve litoloji haritaları
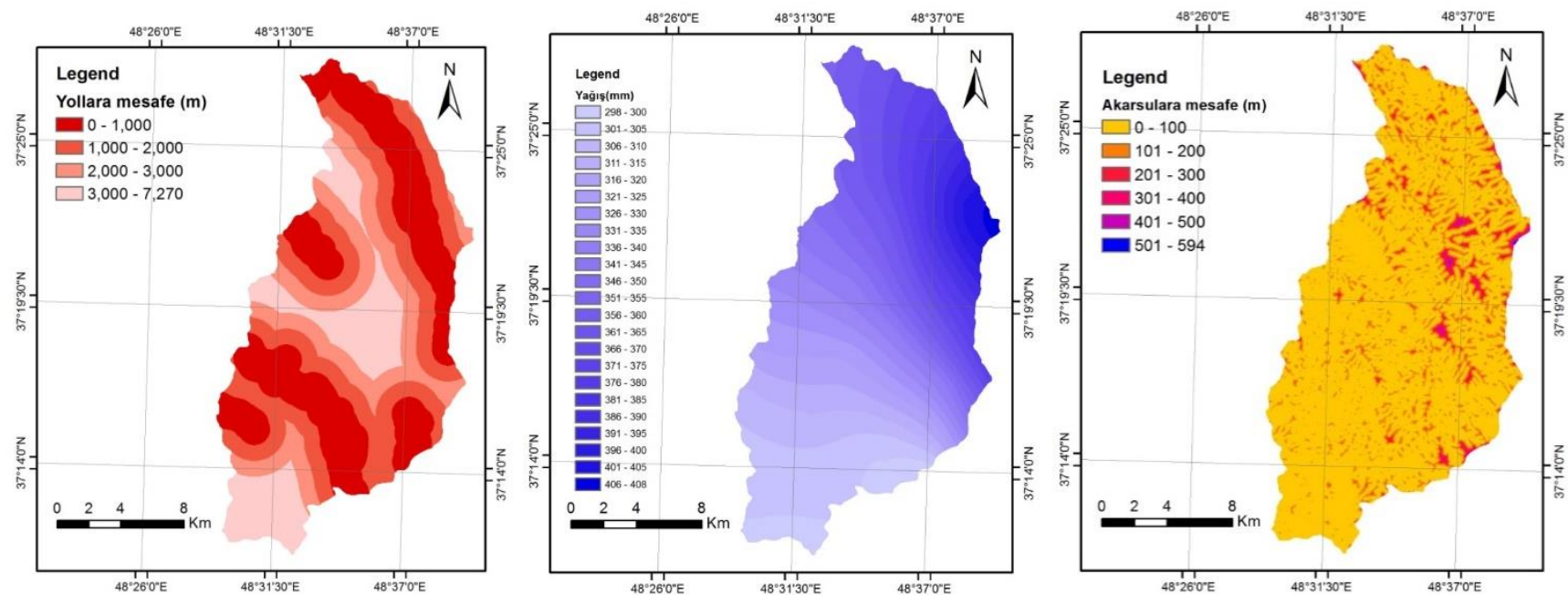

Şekil 5. Yollara mesafe, yağış ve akarsulara mesafe haritaları

Tablo 1. Heyelan Duyarlllkk Analizinde Etkili Olan Faktörler

\begin{tabular}{|c|c|c|c|c|c|}
\hline Kriterler & Alternatifler & Ăğırlık & Kriterler & Alternatifler & Ağırlık \\
\hline \multirow{12}{*}{ Litoloji } & A: Altered zones & 100 & \multirow{5}{*}{$\begin{array}{l}\text { Fay hatlarına } \\
\text { uzaklık (m) }\end{array}$} & $<500$ & 100 \\
\hline & C: Limestone & 0 & & $500-1000$ & 95 \\
\hline & M: Marl and claystone & 80 & & $1000-2000$ & 85 \\
\hline & Q: Alluvial and colluvial deposits & 35 & & $2000-3000$ & 80 \\
\hline & SC: Sandstone and conglomerates & 0 & & $3000-4100$ & 40 \\
\hline & SCM: Sandstone, conglomerate and marl & 10 & \multirow{4}{*}{$\begin{array}{l}\text { Yollara mesafe } \\
(\mathrm{Km})\end{array}$} & $0-1$ & 0 \\
\hline & Sh: Schist and shale & 0 & & $1-2$ & 0 \\
\hline & SL: Sandy to silty limestone & 20 & & $2-3$ & 90 \\
\hline & SP: Phyllite and metamorphic rocks & 0 & & $3-4$ & 100 \\
\hline & V: Volcanic rocks & 0 & \multirow{8}{*}{ Arazi örtüsü } & Mod range & 100 \\
\hline & VT: Lavas and tuffs & 10 & & Poor range & 20 \\
\hline & WV: Weathered and brecciated ext. rocks & 0 & & Mix Bagh & 60 \\
\hline \multirow{8}{*}{ Bak1 } & $\mathrm{N}$ facing $\left(45^{\circ}\right.$ about $\left.\mathrm{N}\right)$ & 0 & & Mix Agri bagh & 60 \\
\hline & $\mathrm{NE}$ facing $\left(45^{\circ}\right.$ about $\left.\mathrm{N} 45^{\circ} \mathrm{E}\right)$ & 40 & & Mix Good range & 70 \\
\hline & E facing $\left(45^{\circ}\right.$ about $\left.\mathrm{E}\right)$ & 80 & & Mix Mod range & 70 \\
\hline & SE facing $\left(45^{\circ}\right.$ about $\left.S 45^{\circ} \mathrm{E}\right)$ & 83.3 & & Agri & 30 \\
\hline & $\mathrm{S}$ facing $\left(45^{\circ}\right.$ about $\left.\mathrm{S}\right)$ & 100 & & Good range & 43 \\
\hline & SW facing $\left(45^{\circ}\right.$ about $\left.\mathrm{S} 45^{\circ} \mathrm{W}\right)$ & 0 & \multirow{3}{*}{$\begin{array}{l}\text { Akarsulara } \\
\text { mesafe (m) }\end{array}$} & $0-100$ & 100 \\
\hline & $\mathrm{W}$ facing $\left(45^{\circ}\right.$ about $\left.\mathrm{W}\right)$ & 0 & & $200-100$ & 100 \\
\hline & $\mathrm{NW}$ facing $\left(45^{\circ}\right.$ about $\left.\mathrm{N} 45^{\circ} \mathrm{W}\right)$ & 0 & & $300-200$ & 90 \\
\hline
\end{tabular}




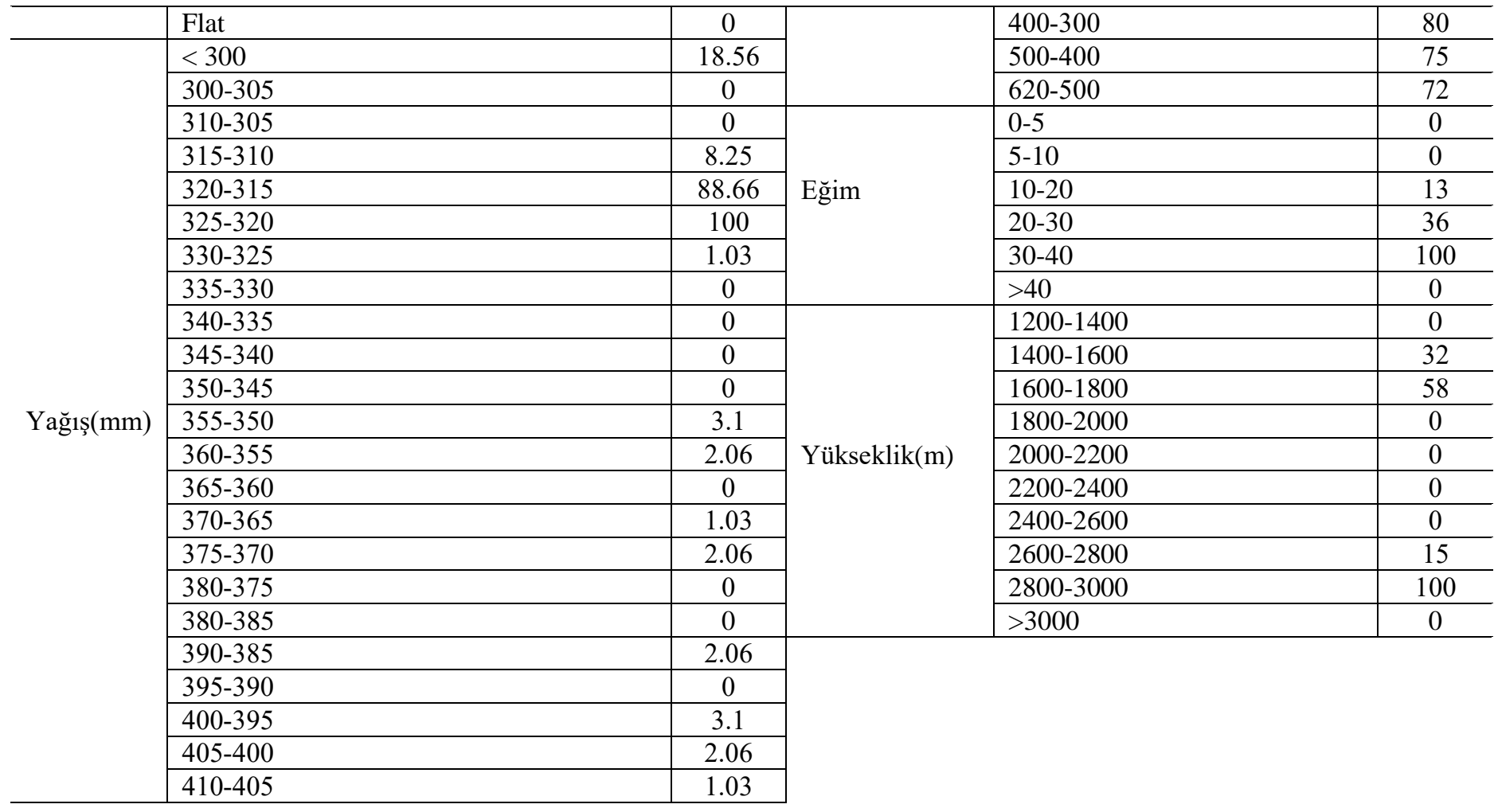

\subsection{Model}

Model oluşturulması için çok kriterli karar verme yöntemleri arasında sıkça başvurulan analitik hiyerarşi süreci AHP' den yararlanılmıştır. Öncelikle çalışma amacı (hedef) belirlenmiş ve bu amaç doğrultusunda seçimi etkileyen kriterler belirlenmiş ve Şekil 6 'da gösterilmiştir. Daha sonra bu kriterler göz önüne alınarak alternatifler tespit edilmiş ve hiyerarşik bir yapı oluşturulmuştur. İlk aşamada tespit edilen kriterler ve alternatifler Saaty (2009) tarafından ortaya konan önem ölçeğine göre kıyaslanmış ve bu ölçek yardımıyla 1 ile 9 arasında derecelendirilmiştir. Bu derecelendirme literatürde bildirilen ölçütlere göre gerçekleştirilmiştir

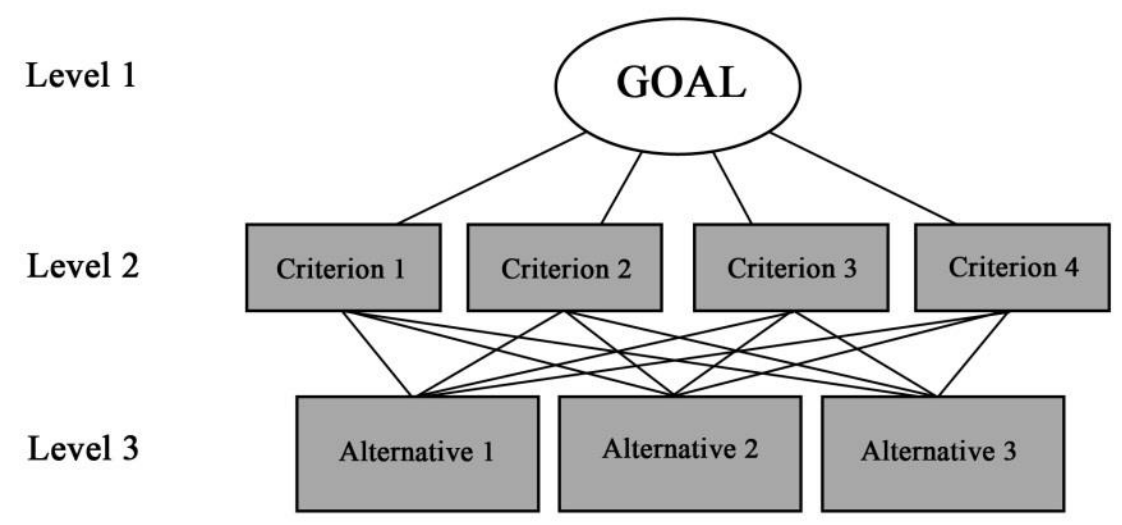

Şekil 6. Zahedi (1986) tarafindan den geliştirilen çok kriterli karar verme için AHP genel yapısı 


\section{Araştırma Sonuçları ve Tartışma}

CBS ortamında, AHP yöntemi kullanarak her kriterin ağırlı̆̆ı hesaplanmış ve Tablo 2'de verilmiştir. Bu sonuçlara göre Şekil 7 'de gösterilen heyelan duyarlılık haritası oluşturulmuştur. Heyelan duyarlılık haritalarının hazırlanmasında CBS temelli AHP yönteminden yararlanılabileceği anlaşılmıştır.

Tablo 2. AHP yöntemi sonuçlart

\begin{tabular}{clcc}
\hline & kriterler & ĂğIrlk(AHP) & Ă̆ırlık (\%) \\
\hline 1 & Akarsulara mesafe & 0.6184581919 & 7 \\
\hline 2 & Arazi örtüsü & 0.3680717154 & 4 \\
\hline 3 & Bakı & 1.9420061382 & 22 \\
\hline 4 & Fay hatlarına uzaklık & 2.1654078242 & 24 \\
\hline 5 & Yükseklik & 0.2005070803 & 2 \\
\hline 6 & Eğim & 1.9873084213 & 21 \\
\hline 7 & Litoloji & 0.5109046485 & 6 \\
\hline 8 & Yollara mesafe & 0.3403116013 & 4 \\
\hline 9 & Yă̆ış & 0.8670243788 & 10 \\
\hline
\end{tabular}

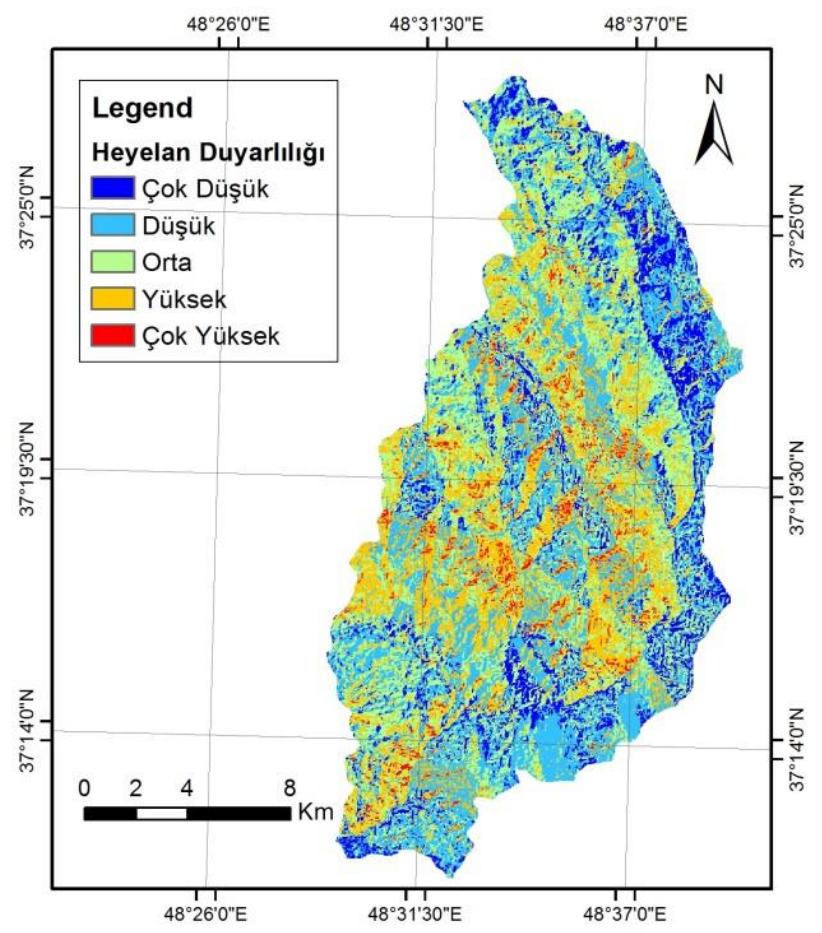

Şekil 7. Heyelan duyarlllık haritası

\section{Değerlendirme}

$\mathrm{Bu}$ çalışmada, Analitik Hiyerarşi Süreci (AHP) yöntemi ve Coğrafi Bilgi Sistemleri (CBS) kullanılarak, İran'ın Ardabil bölgesindeki Saqezchi için bir heyelan duyarlılık haritası hazırlanmıştır. Heyelan duyarlılık haritası oluşturmak için geçmiş araştırmalardan 9 adet parametre seçilmiştir. Her bir parametrenin heyelan oluşumuna katkısı; analitik hiyerarşi süreci yöntemleri kullanılarak incelenmiş ve ağırlık değerleri dikkate alınarak heyelan duyarlılık haritası üretilmiştir.

Heyelan duyarlılık çalışmalarının özellikle afet yönetim planlamalarında kullanılabileceği ve risk haritalarının hazırlanmasında büyük yarar sağlayacağı açıktır. Heyelan duyarlılık haritaları arazi kullanım planlaması için de önemli bir rehber olacaktır. Süregelen çalışmalarda elde edilen bulgular özellikle il/ilçe bazlı çalışmaların gerekliliğini de ortaya koymaktadır. Ayrıca bu tür çalışmaların diğer doğal afetler içinde hazırlanması oldukça mühim bir husustur. 


\section{Kaynakça}

Akgun, A., \& Türk, N. (2010). Landslide susceptibility mapping for Ayvalik (Western Turkey) and its vicinity by multicriteria decision analysis. Environmental Earth Sciences, 61(3), 595-611.

Cevik, E., \& Topal, T. (2003). GIS-based landslide susceptibility mapping for a problematic segment of the natural gas pipeline, Hendek (Turkey). Environmental geology, 44(8), 949-962.

Clerici, A., Perego, S., Tellini, C., \& Vescovi, P. (2006). A GIS-based automated procedure for landslide susceptibility mapping by the conditional analysis method: the Baganza valley case study (Italian Northern Apennines). Environmental Geology, 50(7), 941-961

Corominas, J., van Westen, C., Frattini, P., Cascini, L., Malet, J. P., Fotopoulou, S., ... \& Pitilakis, K. (2014). Recommendations for the quantitative analysis of landslide risk. Bulletin of engineering geology and the environment, 73(2), 209-263.

Crozier, M. J. (1986). Landslides: causes, consequences and environment, Croom Helm. London. 252.

Dai, F. C., Lee, C. F., Li, J. X. Z. W., \& Xu, Z. W. (2001). Assessment of landslide susceptibility on the natural terrain of Lantau Island, Hong Kong. Environmental Geology, 40(3), 381-391.

Feizizadeh, B., \& Blaschke, T. (2013). GIS-multicriteria decision analysis for landslide susceptibility mapping: comparing three methods for the Urmia lake basin, Iran. Natural hazards, 65(3), 2105-2128.

Feizizadeh, B., Roodposhti, M. S., Jankowski, P., \& Blaschke, T. (2014). A GIS-based extended fuzzy multi-criteria evaluation for landslide susceptibility mapping. Computers \& geosciences, 73, 208-221.

Hashemi Tabatabaei, S. (1998). Landslide hazard zonation in southwest of Ardabil Province Iran. Ministry of Roads and Urban Development, Tehran, Iran, 2.

Ilinca, V., \& Gheuca, I. (2011). The Red Lake Landslide (Ucigaşu Mountain, Romania). Carpathian Journal of Earth and Environmental Sciences, 6(1), 263-272.

Lee, S., \& Dan, N. T. (2005). Probabilistic landslide susceptibility mapping in the Lai Chau province of Vietnam: focus on the relationship between tectonic fractures and landslides. Environmental Geology, 48(6), 778-787.

Lee, S., \& Min, K. (2001). Statistical analysis of landslide susceptibility at Yongin, Korea. Environmental geology, 40(9), 1095-1113.

Mohammady, M., Pourghasemi, H. R., \& Pradhan, B. (2012). Landslide susceptibility mapping at Golestan Province, Iran: a comparison between frequency ratio, Dempster-Shafer, and weights-of-evidence models. Journal of Asian Earth Sciences, 61, 221-236.

Nefeslioglu, H. A., Sezer, E., Gokceoglu, C., Bozkir, A. S., \& Duman, T. Y. (2010). Assessment of landslide susceptibility by decision trees in the metropolitan area of Istanbul, Turkey. Mathematical Problems in Engineering, 2010

Özşahin, E. (2014). Tekirdağ ilinde coğrafi bilgi sistemleri ve analitik hiyerarşi süreci kullanarak heyelan duyarlilik analizi. HUMANITAS-Uluslararası Sosyal Bilimler Dergisi, 2(3), 167-186.

Saaty, T. L., \& Brandy, C. (2009). The encyclicon, volume 2: a dictionary of complex decisions using the analytic network process. Pittsburgh, Pennsylvania: RWS Publications.

Talaei, R. (2014). Landslide susceptibility zonation mapping using logistic regression and its validation in Hashtchin Region, northwest of Iran. Journal of the Geological Society of India, 84(1), 68-86.

Talaei, R. (2018). A Combined Model for Landslide Susceptibility, Hazard and Risk Assessment. AUT Journal of Civil Engineering, 2(1), 11-28.

Talaei, R., Ghayoumian, J., Akbarzadeh, E. A., \& Shariat Jafari, M. (2004). Study on Effective Factor Causing Landslide in South West of Khalkhal Region.

Uromeihy, A., \& Mahdavifar, M. R. (2000). Landslide hazard zonation of the Khorshrostam area, Iran. Bulletin of Engineering Geology and the Environment, 58(3), 207-213.

Van Westen, C. J., Seijmonsbergen, A. C., \& Mantovani, F. (1999). Comparing landslide hazard maps. Natural hazards, 20(2-3), $137-158$.

Wang, C., Esaki, T., Xie, M., \& Qiu, C. (2006). Landslide and debris-flow hazard analysis and prediction using GIS in MinamataHougawachi area, Japan. Environmental Geology, 51(1), 91-102.

Yesilnacar, E., \& Topal, T. (2005). Landslide susceptibility mapping: a comparison of logistic regression and neural networks methods in a medium scale study, Hendek region (Turkey). Engineering Geology, 79(3-4), 251-266.

Yilmaz, Işık. "A case study from Koyulhisar (Sivas-Turkey) for landslide susceptibility mapping by artificial neural networks." Bulletin of Engineering Geology and the Environment 68, no. 3 (2009): 297-306.

Zahedi, F. (1986). The analytic hierarchy process - a survey of the method and its applic. 